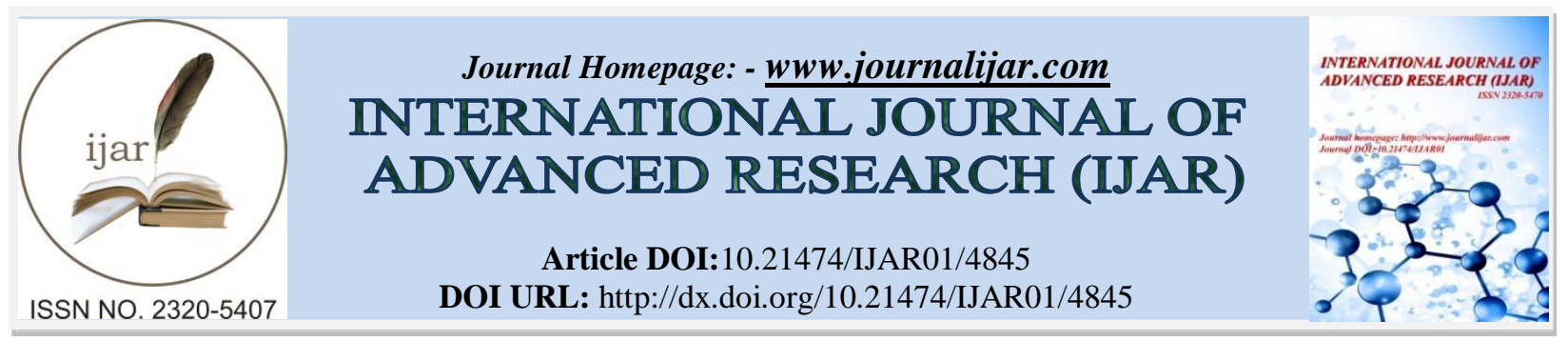

RESEARCH ARTICLE

\title{
COMPARISON OF BERG BALANCE SCALE IN DIFFERENT AGE GROUPS.
}

Vincent Jeyaraj. $D^{1}$, Malarvizhi. $D^{2}$ and Sivakumar. V. P. $\mathbf{R}^{3}$.

1. Assistant Professor, SRM College of Physiotherapy.

2. Associate Professor, SRM College of Physiotherapy.

3. Dean, SRM College of Physiotherapy.

\section{Manuscript Info}

..........................

Manuscript History

Received: 14 May 2017

Final Accepted: 16 June 2017

Published: July 2017

\section{Abstract ABSTRACT}

Objective: The aim of the study is to find the balance among the different age groups.

Methods: study type - one time observational study, sampling method- convenient method, no of samples-30, group a age 45-55=10 samples, group b age 56-65 $=10$ samples, group c age above $65=10$ samples. The balance where assessed using the berg balance scale. Results: The statistical results shows that there is a significant difference of $p<0.05$ in the the age group of above 65 . Hence the balance decreases as age progresses.

Conclusion: The results of this study on "comparison on berg balance scale in different age groups" is used to identify the area of impairment and the effects of the impairment on function of the individual. The study in three different age groups (i.e) $45-55$ years, $56-65$ years \& above 65 years and the end of the study we observe that the balance declines as age progresses $\&$ more balance difference in last age group i.e above 65 years. The results that will restore the patients balance and mobility and also for identifying specific interventions to prevent falls in patients.

Copy Right, IJAR, 2016,. All rights reserved.

\section{Introduction:-}

Balance is a term describing the dynamics of body posture to prevent falling. It is related to the internal forces acting on the body and the internal characteristics of body segments[1]. Balance is a state of equilibrium when the projection of its centre of gravity falls within its base of support and when the resultant of all its forces acting on it is zero. It is complex and is a coordinated response of the neuromuscular and musculoskeletal system.

Gait and balance disorders are among the most common causes of falls in older adults[2]. Aging process is associated with changes to gait patterns and balance. Dizziness and imbalance are one of the most common complaints among older people. The prevalence ranges from approximately $20 \%$ to $30 \%$, depending on the definition of dizziness and the population studied[3]. Some of problems like cerebellar deficit, changes in vestibular system, proprioception deficit and visual deficit.

Effect of age on the stability of stance allows to differentiate between physiological aging and the pathologies leading to impaired balance control[5]. Bone loss is a normal concomitant of ageing and occurs in both genders after peak bone mass has been attained[6]. 
Starting from the middle of the third decade, women lose $35 \%$ of their cortical bone and $50 \%$ of their trabecular bone[7], whereas men lose approximately two thirds of this amount over their respective lifetimes[8]

Brain plasticity or reserve may play an important role in maintenance of mobility in the presence of physiologic impairments and may act to delay or reverse the effects of aging on brain pathology[9].

Balance problem is the most serious public health problem. So, analysis of balance contributes towards identifying situations with risk of falling. The BERG BALANCE test was developed in early 1990's as a means of BERG BALANCE SCALE are used to identify areas of impairment and the effects of the impairment on function. The Berg Balance Scale is an a performance-based assessment tool that is used to evaluate standing balance during functional activities. The patient is scored on fourteen different tasks[4].

The Berg Balance Scale is an a performance-based assessment tool that is used to evaluate standing balance during functional activities. The Berg Balance Scale is a widely used assessment tool to identify balance impairment.The test is often used for patients who exhibit a decline in function, self-report a loss of balance, or have unexplained falls.

\section{Procedure:-}

The subjects were selected according to inclusion of Ability to walk without assistance.

Person without any recent injury, To perform normal activities of daily living (ADL) and Age above 45years of both sexes.and exclusion criteria where Below age group of 45years, Neurological disorder, Psychosomatic problems, Joint pathology in lower limbs and Respiratory problems. The selected samples are splitted according to three age groups where evaluate with berg balance scale. It comprises of 14 items for a maximum score of each item, hence an overall score of 56; it takes about 20 minutes for the administration of the test \& requires equipments like step, stopwatch, chair, scale, inch tape. Studies have concluded that a BERG BALANCE SCALE score of less than 45/56 predicted that individual's needs assistance in the form of aids to maintain standing balance. It is now being widely used as a valuable clinical measure of balance. Evidence of the validity of BERG BALANCE SCALE as a measure of standing balance.

Data analysis:-

\begin{tabular}{|c|c|c|c|c|c|c|}
\hline Age Groups & $\mathrm{N}$ & Mean & Std. Deviation & Std. Error & F - Value & Significance Level \\
\hline Age Group A 45 to 55 & 10 & 53.90 & 2.470 & .781 & \multirow{4}{*}{34.930} & \multirow{4}{*}{.001} \\
\hline Age Group B 56 to 65 & 10 & 49.00 & 3.621 & 1.145 & & \\
\hline Age Group C Above 65 & 10 & 40.20 & 4.709 & 1.489 & & \\
\hline Total & 30 & 47.70 & 6.788 & 1.239 & & \\
\hline
\end{tabular}

Table 1:- From the above table 1, we can see that there is an significant different in mean values of the berg balance scale in various age groups. Also there is a difference of standard deviation. 
Fig 1:-Bar Chart about Different Age Groups.

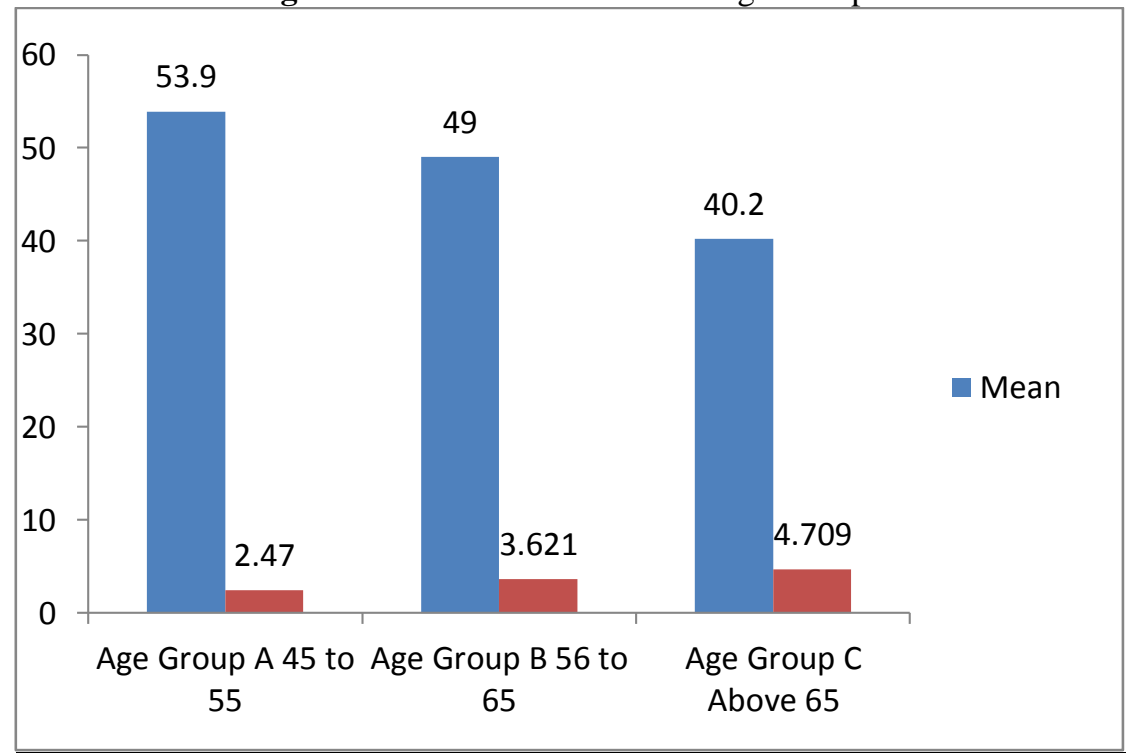

The graph shows that there is an decline of balance as age group increases $p<0.05$.the mean value for the age 45-55 is 53.90 the standard deviation for age 45-55 is 2.470 and the mean value for the age 56-65 is 49 the standard deviation for age 56-65 is 3.621 mean value for the age $>65$ is 40.2 the standard deviation for age $>65$ is 4.709

Fig 2:-Line diagram about different age groups

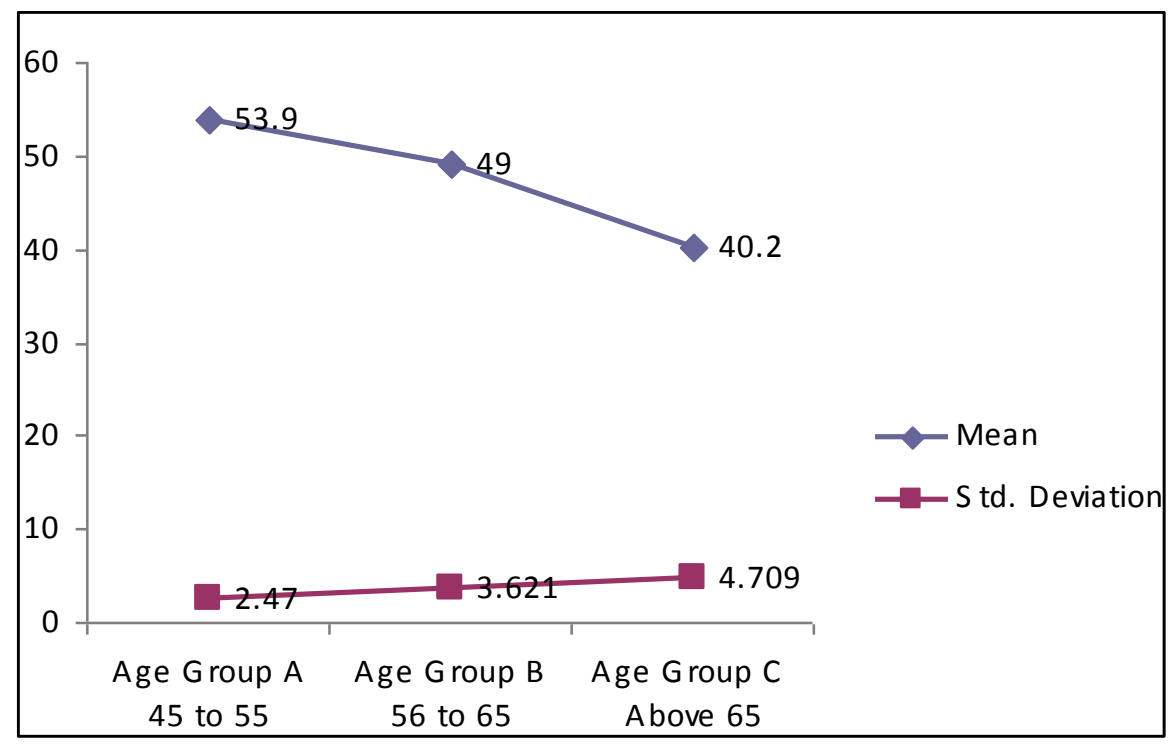

The line diagram shows that there is an decline of balance as age group increases $p<0.05$.the mean value for the age 45-55 is 53.90 the standard deviation for age 45-55 is 2.470 and the mean value for the age 56-65 is 49 the standard deviation for age 56-65 is 3.621 mean value for the age $>65$ is 40.2 the standard deviation for age $>65$ is 4.709 
Fig.3:-Pie Diagram about different Age groups

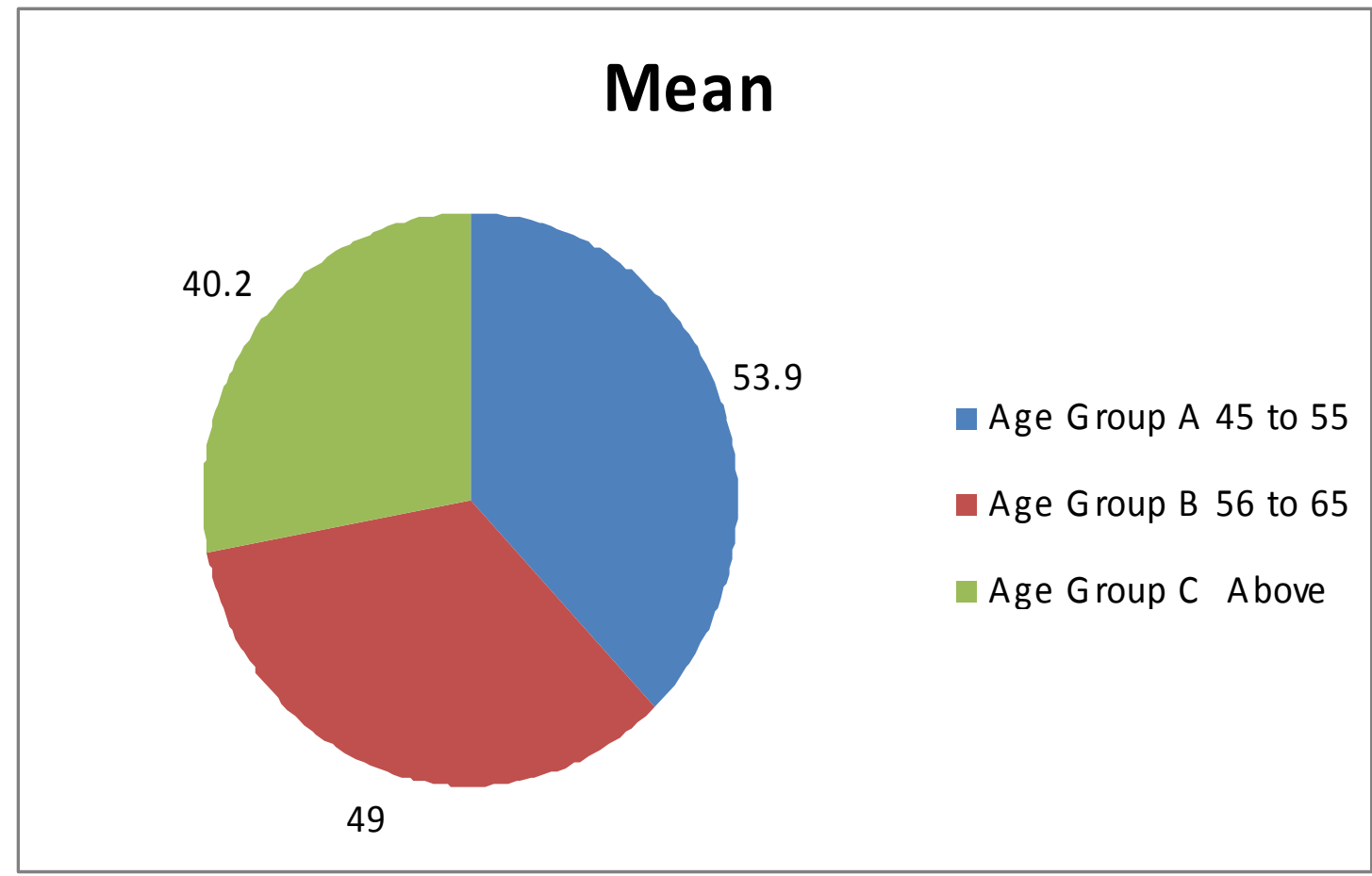

The Pie Diagram shows that there is an decline of balance as age group increases $p<0.05$.the mean value for the age 45-55 is 53.90 the standard deviation for age 45-55 is 2.470 and the mean value for the age 56-65 is 49 the standard deviation for age 56-65 is 3.621 mean value for the age $>65$ is 40.2 the standard deviation for age $>65$ is 4.709 .

\section{Results:-}

The statistical results shows that there is a significant difference of $p<0.05$ in the following age groups. Hence the balance decreases as age progresses.

\section{Discussion:-}

This is a comparative study between the effects of "BERG BALANCE SCALE IN DIFFERENT AGE GROUPS" to find the balance in three different age groups

Balance becomes a function which is assured and taken for granted. It is only when the balance mechanism fails hat is importance is realized.

Aging is associated with decline in the function of the sensory systems. Brain size and weight reduction occurs mainly in the areas of cerebral cortex. It has been widely found that the volume of the brain and/or its weight declines with age at a rate of around 5\% per decade after age 40 [10]. It must be remembered that the brains of an elderly group may show cohort effects related to wider environmental influences, for example, lack of high energy foods while growing up[11].

It is also extremely difficult to separate out and measure single cognitive processes to fully understand any changes [12]. The age related changes in neural, sensory, \& musculoskeletal system can lead to balance impairments.MAKI $\mathrm{BE}$ et al (1990). The central nervous system demonstrates many structural changes during the ageing process. The body sways increases with age consequences of decline in muscle function results in. Posture and sway are evaluated with the subject standing on one or both feet on a stable or unstable base HOFFMANN \& PAYNE (1995). Reduction in ability to perform ADL'S. Change in balance and gait will increased fall risk.

Balance depends on the integrative functioning of many factors like visual, vestibular, proprioceptive, exteroceptive and tactile sources. Musculoskeletal changes such as calcification of tendon and ligament and loss of bone mineral 
content may result in postural changes which in turn may alter the body mechanics and lead to instability and post recovery from loss of balance TIDEIKSARR (1989).

The berg balance scale was designed with the explicit intention of providing a means to determine change in balance ability overtime BERG et al (1989). The speed of balance response may also decrease with ageing as a result of a reduction in the conduction velocity DORFMAN \& BOSLEY (1979).

This study is an attempt to find the relationship between the age and the balance by using berg balance scale. The finding of this study showed that ageing is associated with decline in the balance of an individual.

\section{Conclusion:-}

The results of this study on "comparison on berg balance scale in different age groups" is used to identify the area of impairment and the effects of the impairment on function of the individual. The study in three different age groups (i.e) 45 - 55 years, 56 - 65 years \& above 65 years and the end of the study we observe that the balance declines as age progresses \& more balance difference in last age group i.e above 65 years. The results that will restore the patients balance and mobility and also for identifying specific interventions to prevent falls in patients.

The conclusion of the study is that there is decline of balance as age progresses.

\section{Limitation and recommendation:-}

\section{Limitation:-}

Sizeof the sample is small

Shorter duration of study.

\section{Recommendation:-}

Larger number samples can be taken.

Longer duration study.

Comparison between males and females is recommended.

Other balance scale can be taken.

\section{References:-}

1. D A Winter $\mathrm{PhD}$, PEng gait \& posture 1995 Human balance and posture control during standing and walking

2. BROOKE SALZMAN, MD, Thomas Jefferson University, Philadelphia, PennsylvaniAm Fam Physician. 2010 Jul 1;82(1):61-68 Gait and Balance Disorders in Older Adults

3. Tinetti ME, Williams CS, Gill TM. Dizziness among older adults: a possible geriatric syndrome. Ann Intern Med. 2000;132(5):337-344

4. Brill, Patricia A. Clinical Disorders of Balance, Posture, and Gait. London, England: Arnold Publishers, 2004.

5. DU PASQUIER RA, BLANC Y, SINNREICH M, LANDIS T, BURKHARD P, VINGERHOETS FJG: The effect of aging on postural stability: a cross sectional and longitudinal study. ClinNeurophysiol33:213-218, 2003.

6. Riggs BL, Wahner HW, Melton LJ, Richelson LS, Judd HL, Offord KP. Rates of bone loss in the appendicular and axial skeletons of women: evidence of substantial vertebral bone loss before menopause. J Clin Invest. 1986;77:1487-1491.[PMC free article] [PubMed]

7. Riggs BL, Wahner HW, Seeman E, Offord KP, Dunn WL, Mazess RB, Johnson KA, Melton LJ., III Changes in bone mineral density of the proximal femur and spine with ageing: differences between the postmenopausal and senile osteoporosis syndromes. J Clin Invest. 1982;70:716-723. [PMC free article] [PubMed]

8. Riggs BL, Wahner HW, Dunn WL, Mazess RB, Offord KP, Melton LJ. Differential changes in bone mineral density of the appendicular and axial skeleton with ageing. J Clin Invest. 1981;67:328-335. [PMC free article] [PubMed]

9. Steffener J, Stern Y. Exploring the neural basis of cognitive reserve in aging. BiochimBiophysActa. 2012;1822:467-473.

10. Svennerholm L, Boström K, Jungbjer B. Changes in weight and compositions of major membrane components of human brain during the span of adult human life of Swedes. ActaNeuropathol 199794345-352. 
11. Scahill R, Frost C, Jenkins R. et al A longitudinal study of brain volume changes in normal ageing using serial registered magnetic resonance imaging. Arch Neurol 200360989-994.

12. Hertzog C. Does longitudinal evidence confirm theories of cognitive ageing derived from cross-sectional data? In: Dixon R, Bäckman L, Nilsson L, eds. New frontiers in cognitive ageing. Oxford: Oxford University Press, 200441-64H: Effect of age on body sway assessed by computerized posturography. J Bone Miner Metab23:152-156, 2005.

13. Benjuya N, Kaplanski J. Age-related changes of postural control: the effect of a cognitive task. GerontolClin. . 2001; 47:189-194.

14. FRANSSON PA, KRISTINSDOTTIR EK, HAFSTRÖM A, MAGNUSSON M, JOHANSSON R: Balance control and adaptation during vibratory perturbations in middle-aged and elderly humans. Eur J ApplPhysiol91: 595-603, 2004.

15. DU PASQUIER RA, BLANC Y, SINNREICH M, LANDIS T, BURKHARD P, VINGERHOETS FJG: The effect of aging on postural stability: a cross sectional and longitudinal study. ClinNeurophysiol33:213-218, 2003.

16. CHOY NL, BRAUER S, NITZ J: Changes in women aged 20 to 80 years. J Gerontol A BiolSci Med Sci58:525530, 2003.

17. DU PASQUIER RA, BLANC Y, SINNREICH M, LANDIS T, BURKHARD P,VINGERHOETS FJG: The effect of aging on postural stability: a cross sectional and longitudinal study. ClinNeurophysiol33:213-218, 2003.

18. LORD SR, MENZ HB: Visual contributions to postural stability in older adults. Gerontology 46:306-310, 2000

19. ENRIETTO JA, JACOBSON KM, BALOH RW: Aging effects on auditory and vestibular responses: a longitudinal study. Am J Otolaryngol20: 371-378, 1999.

20. PRIETO TE, MYKLEBUST JB, HOFFMAN RG, LOVETT EG, MYKLEBUST BM Measures of postural steadiness: Differences between healthy young and elderly adults. IEEE Trans Biomed Eng 43:956-966, 1996.

21. MYKLEBUST JB, HOFFMAN RG, LOVETT EG, MYKLEBUST BM: Measures of postural steadiness: Differences between healthy young and elderly adults. IEEE Trans Biomed Eng43:956-966, 1996

22. WOOLLACOTT MH: Age- related changes in posture and movement. $J$ Gerontol48:56-60, 1993.

23. HYTÖNEN M, PYYKKÖ I, AALTO H, STARCK J: Postural control and age. ActaOtolaryngol (Stockh) 113:119-122, 1993.

24. WOODHULL-MCNEAL AP: Changes in posture and balance with age. Aging ClinExp Res, 4:219-225, 1992

25. TEASDALE N, STELMACH GE, BREUNING A: Postural sway characteristics of the elderly under normal and altered visual and support conditions. J Gerontol46:B238- 244, 1991.

26. MICHAELL.BARNETT journel of management studies volume 43, issue 8, pages1753-73 blackwell publishing ltd2006.

27. MANCHESTER D, WOOLLACOTT M, ZEDERBAUER-HYLTON N, MARIN O: Visual, vestibular and somatosensory contributions to balance control in the older adult. J Gerontol Med Sci44: M118-127, 1989. 